\title{
Bilateral Melolabial Flap Reconstruction Post Fibrotomy: A Novel Alternative Option
}

\author{
Shriya Mandal ${ }^{1}$, Sobhan Mishra ${ }^{2}$, Harshmohan Pathak ${ }^{3}$, Sudipta Sahu ${ }^{4}$
}

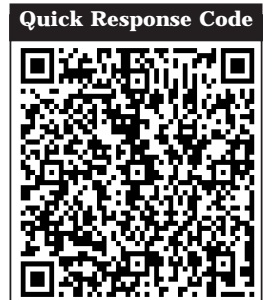

\section{doi: $10.5866 / 2016.8 .10128$}

${ }^{1}$ Post Graduate Student

${ }^{2}$ Professor \& HOD

${ }^{3}$ Assistant Professor

${ }^{4}$ Post Graduate Student

Department of Oral \& Maxillofacial Surgery, IDS,

Bhubaneswar

\section{Article Info:}

Received: April 12, 2016

Review Completed: May 11, 2016

Accepted: J une 10, 2016

Available Online: September, 2016 (www.nacd.in)

(C) NAD, 2016 - All rights reserved

Email for correspondence:

drsudiptaomfs@gmail.com

\begin{abstract}
:
Melolabial flap previously known as nasolabial flap is a proven reconstructive option for correcting defects of the face preferably of the nose and forehead. Two subtypes based on different pedicles exists namely superiorly and inferiorly pedicled melolabial flap. Melolabial flap can also be successfully incorportated through the raised tunnel to correct various defects of the buccal mucosa. The present case report highlights the usefulness of the bilateral melolabial flap as an alternative method to reconstruct buccal mucosa defect of a oral submucous fibrosis case treated by fibrotomy.
\end{abstract}

Key words: Melolabial flap, Nasolabial Flap, Oral submucous fibrosis, Reconstruction.

\section{INTRODUCTION:}

Oral Submucous fibrosis (OSMF) is a potentially malignant condition which is extensively found in the Indian subcontinent predominantly due to the betel quid and areca nut chewing habit. J oshi was the first to coin the term Oral Submucous Fibrosis. Schwarz in 1952 described the OSMF as a premalignant condition in his study upon five Indian origin women in Africa, though recent WHO reclassifies it as a potentially malignant condition. ${ }^{1,2}$

OSMF has a characteristic feature of juxta- epithelial inflammation and fibrosis, mostly along with progressive atrophy of the overlying epithelium, keratinizing metaplasia, increased deposition of hyalinised collagen underneath the basement membrane, and a progressive loss of vascularity to the mucosa giving a pale glossy smoothened look. ${ }^{3}$

OSMF thus causes progressive loss of mouth opening with a burning sensation and advanced cases have reported to transform into squamous cell carcinoma as well as verrucous carcinoma. ${ }^{4-6}$ 
Andrade and Khanna classified various stages of OSMF and proposed treatment protocols According to stages. ${ }^{7}$ Advanced OSMF with mouth opening less than $25 \mathrm{~cm}$ are ideally candidates for surgical correction namely fibrotomy and reconstruction of the defect.

Various Reconstructive options have been proposed including split thickness skin graft, radial forearm free flap, pedicled buccal fat pad and melolabial flap. Melolabial flap as described in the sushruta samhita has evolved through ages to become one of the prime reconstructive options for correction of or ofacial defects ${ }^{8}$.

\section{CASE REPORT:}

A 25 year old male patient reported to the department of Oral and Maxillofacial Surgery, IDS, Bhubaneswar with the complaint of inability to open mouth properly sincethelast 3 years. Hehad a habit of chewing areca nut and catechu for the last 7 years. He did not discontinue his habit until advised to do so and on examination, had a mouth opening of maximal interincisal distance of 10mm (Figure 1). On intraoral palpation there were severe fibrotic bands bilaterally both horizontally and vertically in the buccal mucosa though no ulceration or any exophytic growth was present intraorally.

The patient was graded as stage $4 \mathrm{~A}$ according to Andrade classification and planned for surgical release of fibrotic bands and inferiorly based melolabial flap reconstruction bilaterally under general anaesthesia.

The patient was nasoendotrachealy intubated by fiberoptic video intubation method due to the extensive limited mouth opening and surgical excision of the fibrotic bands was achieved by combination of scalpel and electrocautery. U pon release of the bands the mouth opening achieved was $36 \mathrm{~mm}$ thus obviating the need for coronoidectomy.

Bilateral inferiorly based melolabial flap marking was done (Figure 2), flap was harvested (Figure 3 and 4) and transbuccal transfer of the flap was done through a tunnel created over the excised defect in the buccal mucosa which covered both the anterior and posterior defects (Figure 5). Tissue excised was sent for histopathological examination to rule out any malignant changes.

Both the flaps were secured to the defect with 4.0 resorbable sutures (Figure 6) and a gauze pack bung was secured to prevent any untoward complications and was removed on $4^{\text {th }}$ post operative day. The patient was on prophylactic antibiotic therapy and nasogastric feeding for the post operative period. The melolabial flap donor site was meticulously closed using 4.0 prolene non absorbable sutures which was removed on $5^{\text {th }}$ post operative day. Progressive oral physiotherapy using icecream sticks was started on $5^{\text {th }}$ post operative day and the maxmal interincisal distance measured was $30 \mathrm{~mm}$ on $14^{\text {th }}$ post operative day (Figure 7 and 8). Mucosalization of the melolabial flap was also seen and patient was informed for the need for eplication in future and scar revision in the region of mel olabial flap donor site.

The histopathological specimen revealed no malignant transformation though features of OSMF were persistant. The patient was recalled on a progressive schedule to note any complications and was also monitored for the maximum interincisal opening.

\section{DISCUSSION:}

The areca nut is considered the main factor causing OSMF. The areca nut generates free radicals and causes local immunosuppression along with decreased collagenolysis capability of the mucosa. ${ }^{9}$ Other etiology and causative agents have also being in literature. ${ }^{10,11}$

Melolabial flap is a random pattern flap nurtured on the vascular supply from thetransverse facial and angular vessels for the inferior and superiorly based flap respectively. It is a simple, effective, and safe flap. Donor site morbidity is very rare. It effectively covers both posterior and anterior defect of fibrotomy in cases of OSMF and due to its mucosalization it rarely caused post operative contracture and refibrosis.

Surgical descriptions about mel olabial flap were found as early as 1830 when Dieffenbach used melolabial flaps to reconstruct nasal alar defects. In 1864, Von Langenbeck used the melolabial flap 


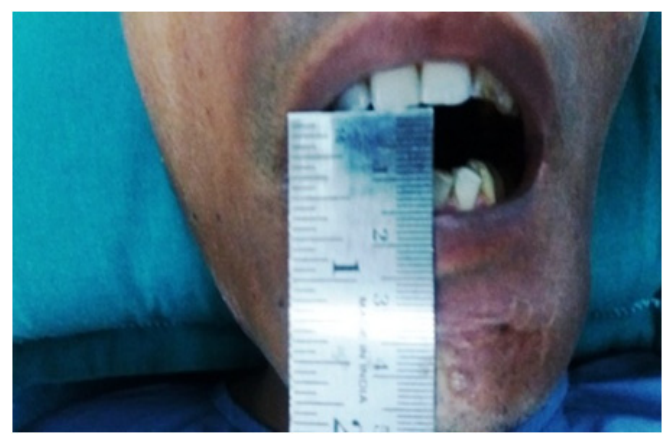

Figure 1: Preoperative interincisal distance measuring about10-15 Mm

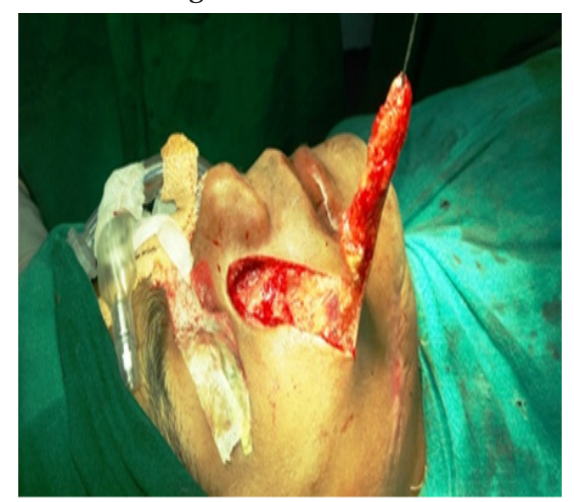

Figure 3: Raising the flap on right side

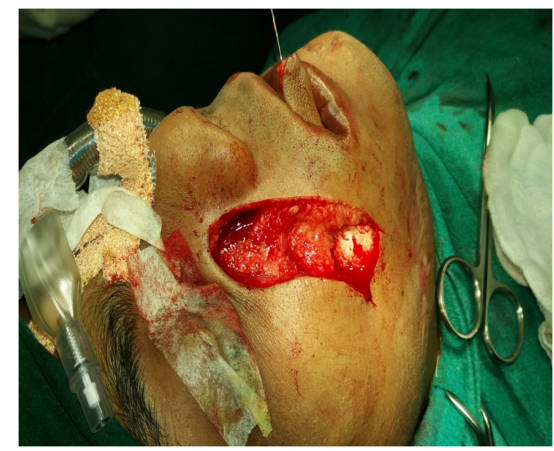

Figure 5: Transbuccal transfer of flap

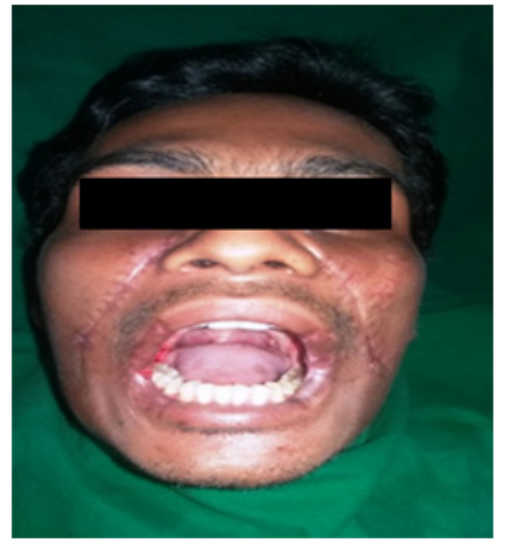

Figure 7: Post operative picture showing improved mouth opening after 1 week

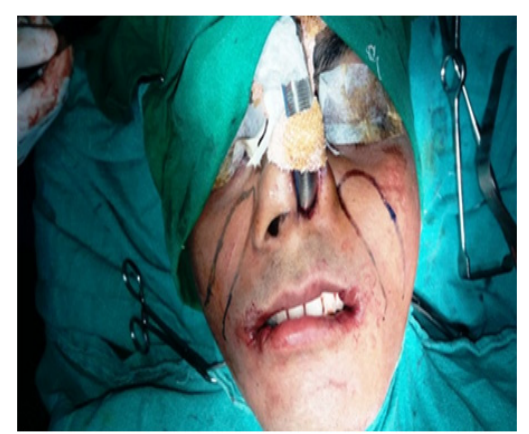

Figure 2: Markings of bilateral melolabial flap

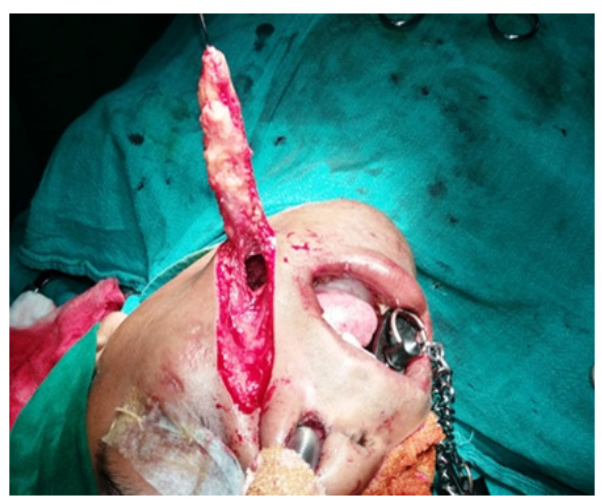

Figure 4: Raising the flap on left side

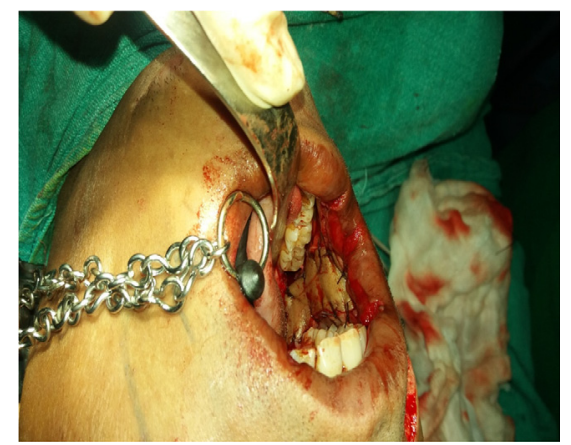

Figure 6: Securing the flap to the defect

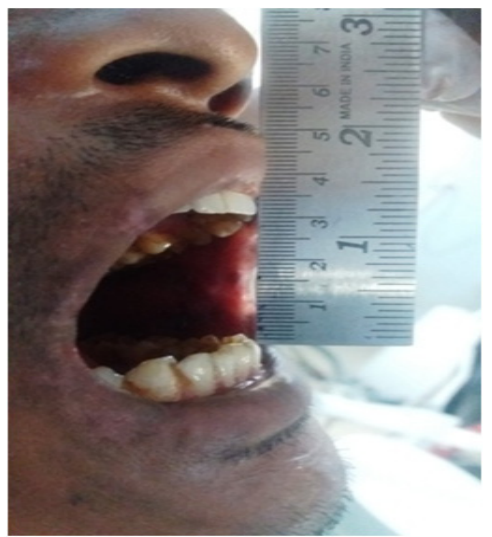

Figure 8: Post operative picture showing increased interincisal distance. 
to reconstruct the nose following ablative therapy. Inferiorly based meolabial flap is a reliable, economical option for the management of oral submucous fibrosis.

The most common complication with the use of melolabial flap is the presence of extraoral scar and intraoral hair growth over the flap. Garatia et al recommended the use of a cheek rotation flap for aesthetic postoperative scar revision. ${ }^{12}$

Various literature havesupported buccal fat pad as a reconstructive option for post fibrotomy reconstruction due to its easy harvesting natureand esthetic purpose. Anshul Rai compared the effectiveness of both melolabial flap and buccal fat pad in a series of fibrotomy cases and concluded the use of buccal fat pad due to its aesthetic efficacy. ${ }^{13}$ Pradhan et al did a comparative study to evaluate buccal fat pad and collagen sheets for defect closure and concluded collagen sheet is superior in outcome compared to buccal fat pad. ${ }^{14}$

Borle R on his 25 advanced OSMF case series did melolabial flap reconstruction along with coronoidectomy and concluded it being an effective reconstructive option though the concern being the presence of extra oral scars. ${ }^{15}$

\section{CONCLUSION:}

The inferiorly based melolabial flap is a good alternative option for reconstruction of OSMF fibrotomy defects. The external melolabial scar is not devastating and when properly corrected as it lies hidden in the melolabial crease though it can be revised surgically at a later stage.

\section{REFFERENCES:}

1. Angadi PV, Rekha K: Oral submucous fibrosis: a clinicopathologic review of 205 cases in Indians. Oral Maxill ofac Surg 2011; 15:19.

2. Warnakulasuriya.S, J ohnsonN.S., van der Waal.I :Nomenclature and classification of potentially malignant disorders of the oral mucosa. J Oral Pathol Med 2007; 36: 575-580.

3. PindborgJ J , Chawla TN, Srivastava AN: E pithelial changes in oral submucous fibrosis. Acta Odontol Scand 1965; 23:277-286.
4. Murti PR, Bhonsie B, Pindborg J J , Daftary DK, Gupta PC and Mehta FS. Malignant transformation rate in oral submucous fibrosis over a 17-year period Community Dent Oral Epidemiol 1985; 13:340-341.

5. Arora R, Adwani D, Naphade M, Bhagat B, Qureshi A. Malignant Conversion of Oral Submucous Fibrosis in Surgically Treated Case. J CDR 2014;8(10):ZD31-ZD32.

6. Pravda C, Srinivasan H, Koteeswaran D, Arathy ML. Verrucous carcinoma in association with oral submucous fibrosis. Indian J of Dent Res. 2011; 22(4):1-3.

7. Khanna J N, Andrade NN. Oral submucous fibrosis: A new concept in surgical management: Report of 100 cases. Int J Oral Maxillofac Surg. 1995; 24:433-439.

8. Mukherjee AL. Oral submucous fibrosis - A search for aetiology. Ind J Otolaryngol 1972; 24:11-15.

9. Lal D. Diffuse oral submucous fibrosis. All India Dent Assoc 1953; 26:1-3.

10. Tilakaratne WM, Klinikowski MF, Saku T: Oral submucous fibrosis: review on etiology and pathogenesis. Oral Oncol 2006; 42:561-568.

11. Canniff J P, Harvey W, Harris M. Oral submucous fibrosis: its pathogenesis and management. Br Dent J 1986; 160:429434

12. Garatea J, Buenechea R, Bescos C, Gonzalez E, Bassas C: Intraoral reconstruction with the nasolabial island flap: a modified technique. J Craniomaxillofac Surg 1991; 19:119122.

13. A. Rai et al. I s buccal fat pad a better option than nasolabial flap for reconstruction of intraoral defects after surgical release of fibrous bands in patients with oral submucous fibrosis? A pilot study: A protocol for the management of oral submucous fibrosis. J Cranio-Maxillo-Facial Surg 2014; 42:111-116.

14. Pradhan. $\mathrm{H}$. et al Two wound-covering materials in the surgical treatment of oral submucous fibrosis: a clinical comparison. J Oral Bio Craniofacial Res 2012 ; 2:10-14.

15. R.M. Borle et al. Extended nasolabial flaps in the management of oral submucous fibrosis. B J Oral Max Surg 2009; 47:382-385.

\section{Gain quick access to our journal online View our journal at www.nacd.in}

